\title{
Shift-work job stress, psychological distress, and job satisfaction
}

\section{among employees}

\author{
Prathana Dodia ${ }^{1 *}$, Neha Parashar ${ }^{2}$
}

\section{ABSTRACT}

The objective of the study was to identify the relationship between Job Stress, Psychological Distress, and Job Satisfaction among employees in comparison to day shift and night shift. The sample consisted of 60 employees, divided equally in both shifts (30-day shift and 30night shift) and selected randomly with simple random sampling technique and volunteer sampling technique. The research tools used are Occupational Stress Index (OSI) to measure job stress, General Health Questionnaire (GHQ-28) to measure psychological distress, and Job Satisfaction Scale (JSS) to measure job satisfaction. For the analysis, Independent Sample t-test and Pearson's Correlation were used to identify and compare the relationship between the independent variables (Day shift and Night shift) and dependent variables (Job Stress, Psychological Distress, and Job Satisfaction). The research findings examined by Independent Samples t-test on GHQ-28 $(\mathrm{t}(45)=-3.655, \mathrm{p}=0.001)$, OSI $(\mathrm{t}(58)=-4.538, \mathrm{p}=$ $0.000)$, JSS $(\mathrm{t}(58)=-5.126, \mathrm{p}=0.000)$, was found to be statistically significant, where the night shift employees experienced more psychological distress and job stress, and low job satisfaction compared to the day shift employees. Pearson's correlation, suggests a positive correlation between GHQ and OSI $(\mathrm{r}=0.541)$, and negative relation between GHQ and JSS $(r=-0.589)$, and OSI and JSS $(r=-0.669)$, which were all significant at the 0.01 level. The results indicate that the employees working in night shift experienced higher Job Stress and Psychological Distress, and Low Job Satisfaction than day shift.

Keywords: Job stress, Psychological distress, Job satisfaction, Day shift, Night shift, Employees

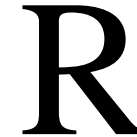

emarkable growth has been witnessed in the shift work schedules in the recent time, particularly among the developing countries, one of which is India. In today's millennial world stress among employees has become a key concern. When one is transitioning from academic life to work life, should be aware that stress is something that one will encounter certainly. For the purpose of the research study the definition by (Luthans 2011) is considered, that defines stress as "An adaptive response that due to any external situation results in physical, psychological and/or behavioral difference for organizational

\footnotetext{
${ }^{1}$ Department of Psychology, Montfort College, Bangalore, Karnataka, India ${ }^{2}$ Department of Psychology, Montfort College, Bangalore, Karnataka, India *Responding Author
}

Received: August 22, 2020; Revision Received: September 21, 2020; Accepted: September 23, 2020

(C) 2020, Dodia P. \& Parashar N.; licensee IJIP. This is an Open Access Research distributed under the terms of the Creative Commons Attribution License (www.creativecommons.org/licenses/by/2.0), which permits unrestricted use, distribution, and reproduction in any Medium, provided the original work is properly cited. 
workers." An individual experiences stress when faced with extraordinary demands, heavy work-load, work-life imbalance, and conflicts that causes a state of tension.

\section{Work-Related Stress}

(Lee Larson 2004), states that any form of mismanaged stress leads to psychological, physical, and behavioral problems along with job dissatisfaction among workers. Stress is caused by various types of stressors such as task demands, role ambiguities, role conflicts, work intensification, ethical dilemmas, interpersonal problems, career development, and physical setting. As per Brief et. al. 1981, stress does not always have a negative influence; it can be triggered by both desirable and undesirable events in life. Stress occurs based on a person's response, where constructive stress or eustress helps in stimulating creativity, encouraging higher diligence, and promoting work effort. Destructive stress or distress is considered dysfunctional for the organization and the individual as it breaks down the person mentally and physically causing job dissatisfaction, reduced performance, unethical behavior, and illness, (Selye 1975). For some employees working night shift would be flexible but for others it does have negative impact causing disturbance in circadian rhythms affecting regular sleep-wake cycle, work-life balance, work performance, and deteriorating physical and mental health, (Costa, G., 1996; Kim, et al., 2002; Rameshbabu, et. al., 2013; Kang, et al., 2017; Verma, et. al., 2018)

\section{Occupational Stress}

Stress experienced at workplace is known as occupational stress that not only causes physical strain but also psychological harm, (Edwards and Burnard 2003). This produces an imbalance between individual capabilities and work demands which leads to burnout, job dissatisfaction, reduced efficiency, poor morale, and labor turnover, (Sutherland \& Cooper, 1990; Blaug, et. al., 2007).

\section{Psychological Distress}

Diurnal creatures as humans, staying up at night and sleeping during the day time are not well conditioned for physical and psychological self (Costa 2010). Shift workers often complain about sleep deprivation which leads to forgetfulness, lack of interest, low energy, irritability, nervousness, anxiety, fatigue, moodiness, that may result in depression, (Scott, et. al., 1997; Drake, et. al., 2004; Åkerstedt \& Wright, 2009; Culpepper, 2010). There is seen a prominent reduction is coping with stress, and resistance to avert psychological problems (Saijo, et. al., 2008). Work-life balance due to night shift suffers as well due to decrease in social activities compared to the day shift workers, (Schwartz J. R., 2010).

\section{Job Satisfaction}

Job satisfaction according to (Kepler, K. 1994), is a state of mind or one's feeling of satisfaction in regards to the work. This is not a form of self-contentment, self-satisfaction or happiness, but a satisfaction on their job that acts as a motivation to keep working. However, during the night time, the supervision from administrators is less where competitiveness and performance among workers decreases with lower promotion and career stagnation. When job satisfaction is higher the performance and productivity level at work increases, indicating a positive relationship, (Judge, et. al., 2001).

Shiftwork offers night workers to engage in solitary hobbies during the day time. However, night shift employees often complain that due to disrupted sleeping time, their socialization and enjoying leisure time gets affected, (Colligan \& Rosa, 1990). The situation worsens as contact with friends and family members become inconvenient. Better adjustment is shown 
for night-shift workers who can sleep at any unusual day time offering flexibility over rigidity, allowing them to overcome drowsiness, (Folkard, et. al., 1979). Thus, workers who can adjust well to the shiftwork are highly satisfied, with less occupational stress and psychological distress.

\section{AIM AND METHODOLOGY}

Objectives

1. To determine the statistically significant difference between day-shift and night-shift employees.

2. To understand the relationship between Job Stress, Psychological Impact, and Job Satisfaction among day-shift and night-shift employees.

\section{Hypothesis}

$\mathrm{H}_{0}$ : There will be no significant difference between Job Stress, Psychological Impact, and Job Satisfaction among night shift workers compared to day shift workers.

$\mathrm{H}_{1}$ : Employees working night shift will have more Job Stress and Psychological Impact, and Low Job Satisfaction than day shift.

\section{Research Tools}

General Health Questionnaire (GHQ-28) developed by David Goldberg and Hiller (1978)The GHQ-28 is a measure with 28 -item screening emotional/psychological distress. It consists of four subscales: somatic symptoms (items 1-7); anxiety/insomnia (items 8-14); social dysfunction (items 15-21), and severe depression (items 22-28).

Occupational Stress Index (OSI) developed by Dr. A.K. Srivastava \& Dr. A.P. Singh (1984)- The OSI is a questionnaire consisting of 46 items with 12 dimensions related to all work life components causing stress.

Job Satisfaction Scale (JSS) developed by Dr. Amar Singh \& Dr. T.R. Sharma (1986)- The JSS consists of 30 statements evaluating satisfaction/dissatisfaction of an employee to his/her job.

Reliability and Validity of the above-mentioned scales used in the study are found to be adequate.

\section{Procedure}

The subjects were divided into two groups of 30 members each shift (30-day shift and 30night shift) and selected randomly with simple random sampling technique and volunteer sampling technique. Participants were given an informed consent form which explained about the study and the confidentiality, and asked for their voluntary participation in the research. Demographic details were gathered based on sex, age, marital status, occupation level, housing, and more through a self-report questionnaire. Questionnaires based on OSI, GHQ-28, and JSS were administered to understand the Job Stress, Psychological Impact, and Job Satisfaction among day shift and night shift employees. For the analysis of data, manuals were used to understand the norms of scoring accurately. Further data was analysed with the help of Statistical Package for the Social Sciences (SPSS Version 23 for Mac) by using Independent Sample T-test and Pearson two-tailed correlation. After the analysis, the interpretation of the results obtained was shared with those participants who requested for it. 
RESULTS AND DISCUSSION

Table 1 Socio-Demographic Details: Comparison Between Day Shift and Night Shift

Employees.

\begin{tabular}{|c|c|c|c|c|c|}
\hline \multicolumn{2}{|l|}{ Variables } & \multicolumn{2}{|c|}{ Day Shift $(n=30)$} & \multicolumn{2}{|c|}{ Night Shift $(n=30)$} \\
\hline \multirow{3}{*}{$\begin{array}{l}\text { Age (Years) } \\
m \pm S D\end{array}$} & $18-30$ & 24 & \multirow{3}{*}{$15 \pm 12.73$} & 25 & \multirow{3}{*}{$15 \pm 14.14$} \\
\hline & $31-50$ & 6 & & 5 & \\
\hline & $50+$ & 0 & & 0 & \\
\hline \multirow[t]{2}{*}{ Gender, $n(\%)$} & Male & \multicolumn{2}{|l|}{$16(53)$} & \multicolumn{2}{|l|}{$27(90)$} \\
\hline & Female & \multicolumn{2}{|l|}{$14(47)$} & \multicolumn{2}{|l|}{$3(10)$} \\
\hline \multirow[t]{3}{*}{ Marital Status, $n(\%)$} & Single & \multicolumn{2}{|l|}{$22(73)$} & \multicolumn{2}{|l|}{$18(60)$} \\
\hline & Married & \multicolumn{2}{|l|}{$8(27)$} & \multicolumn{2}{|l|}{$12(40)$} \\
\hline & Divorced/Widowed & \multicolumn{2}{|l|}{$0(0)$} & \multicolumn{2}{|l|}{$0(0)$} \\
\hline \multirow{4}{*}{$\begin{array}{l}\text { Educational Level, } \\
n(\%)\end{array}$} & $12^{\text {th }}$ Grade or Less & \multicolumn{2}{|l|}{$5(17)$} & \multicolumn{2}{|l|}{$4(13)$} \\
\hline & $\begin{array}{l}\text { High School } \\
\text { Graduate or GED }\end{array}$ & \multicolumn{2}{|l|}{$0(0)$} & \multicolumn{2}{|l|}{$7(23)$} \\
\hline & Under-Graduate & \multicolumn{2}{|l|}{$16(53)$} & \multicolumn{2}{|l|}{$9(30)$} \\
\hline & Post-Graduate & \multicolumn{2}{|l|}{$9(30)$} & \multicolumn{2}{|l|}{$10(33)$} \\
\hline \multirow{2}{*}{$\begin{array}{l}\text { Occupational Status, } \\
n(\%)\end{array}$} & Clerk & \multicolumn{2}{|l|}{$21(70)$} & \multicolumn{2}{|l|}{$20(67)$} \\
\hline & Manager & \multicolumn{2}{|l|}{$9(30)$} & \multicolumn{2}{|l|}{$10(33)$} \\
\hline \multirow{4}{*}{$\begin{array}{l}\text { Job Seniority } \\
\text { (Years), } m \pm S D\end{array}$} & $0-5$ & 24 & \multirow{4}{*}{$15 \pm 12.73$} & 16 & \\
\hline & $6-11$ & 6 & & 10 & $10 \pm 6$ \\
\hline & $12-17$ & 0 & & 4 & \\
\hline & $>17$ & 0 & & 0 & \\
\hline Job Contract, $n(\%)$ & Permanent & $25(83)$ & & $24(80)$ & \\
\hline & Fixed Term & $5(17)$ & & $6(20)$ & \\
\hline Working Hours, $n$ & Full Time & $29(97)$ & & $25(83)$ & \\
\hline (\%) & Part Time & $1(3)$ & & $5(17)$ & \\
\hline Commuting Time to & $<60$ Minutes & $18(60)$ & & $21(70)$ & \\
\hline Work, $n(\%)$ & $>60$ Minutes & $12(40)$ & & $9(30)$ & \\
\hline
\end{tabular}

Socio-demographic details, (Table1) examined for the 60 participants, shows that younger (18-30 years) male employees compared to female employees tend to work in night shifts more than day shift. The personnel characteristics of the participants help in understanding their perspective about the problem particularly. The job stress, psychological impact, and job satisfaction could be understood well by identifying the external variables such as educational level, job seniority, and job status, commuting time to work, working hours, and marital status.

\section{Independent Sample t-test}

In order to study the relationship between the Job Stress, Psychological Impact, and Job Satisfaction among employees in relation to night shift and day shift, an independent sample t-test was conducted.

Table 2 Illustrating the descriptive statistics of GHQ-28

\begin{tabular}{|l|l|l|l|l|}
\hline \multirow{2}{*}{ GHQ-28 } & Shift-Schedule & N & Mean & Std. Deviation \\
\hline & Dayshift & 30 & 2.90 & 3.556 \\
\cline { 2 - 5 } & Nightshift & 30 & 7.80 & 6.424 \\
\hline
\end{tabular}


Shift-work job stress, psychological distress, and job satisfaction among employees

Table 2.1 Illustrating the Independent Samples t-test of GHQ-28

\begin{tabular}{|l|l|l|l|l|l|l|}
\hline \multicolumn{2}{|c|}{} & \multicolumn{2}{l|}{$\begin{array}{l}\text { Levene's Test for } \\
\text { Equality of Variances }\end{array}$} & \multicolumn{2}{l|}{ t-test for Equality of Means } \\
\cline { 2 - 7 } \multicolumn{2}{|l|}{} & F & Sig. & t & df & $\begin{array}{l}\text { Sig. (2- } \\
\text { tailed) }\end{array}$ \\
\hline $\begin{array}{l}\text { GHQ- } \\
28\end{array}$ & $\begin{array}{l}\text { Equal variances } \\
\text { assumed }\end{array}$ & 4.424 & .040 & 3.655 & 58 & .001 \\
\cline { 2 - 7 } & $\begin{array}{l}\text { Equal variances } \\
\text { not assumed }\end{array}$ & & & 3.655 & 45.246 & .001 \\
\hline
\end{tabular}

The test was found to be statistically significant, $\mathrm{t}(45)=-3.655, \mathrm{p}=0.001$, as the Sig. $p \leq$ 0.05 , it concludes that the equal variances not assumed. Since Sig. $=0.040$ in Table 2.1, the bottom row of t-test is considered and denoted as equal variances not assumed. These results indicate that night shift employees $(\mathrm{M}=7.80, \mathrm{SD}=6.424)$ experienced more psychological distress compared to the day shift employees $(\mathrm{M}=2.90, \mathrm{SD}=3.556)$.

Table 3 Illustrating the descriptive statistics of Occupational Stress Index.

\begin{tabular}{|l|l|l|l|l|}
\hline & Shift-Schedule & N & Mean & Std. Deviation \\
\hline \multirow{2}{*}{ OSI } & Dayshift & 30 & 127.73 & 11.847 \\
\cline { 2 - 5 } & Nightshift & 30 & 145.00 & 17.146 \\
\hline
\end{tabular}

Table 3.1 Illustrating the Independent Samples t-test of Occupational Stress Index.

\begin{tabular}{|l|l|l|l|l|l|l|}
\hline \multicolumn{2}{|c|}{} & \multicolumn{2}{|l|}{$\begin{array}{l}\text { Levene's Test for } \\
\text { Equality of Variances }\end{array}$} & \multicolumn{2}{l|}{ t-test for Equality of Means } \\
\cline { 2 - 7 } \multicolumn{2}{|c|}{} & F & Sig. & t & df & $\begin{array}{l}\text { Sig. (2- } \\
\text { tailed) }\end{array}$ \\
\hline \multirow{2}{*}{ OSI } & $\begin{array}{l}\text { Equal variances } \\
\text { assumed }\end{array}$ & 1.023 & .316 & 4.538 & 58 & .000 \\
\cline { 2 - 7 } & $\begin{array}{l}\text { Equal variances } \\
\text { not assumed }\end{array}$ & & 4.538 & 51.548 & .000 \\
\hline
\end{tabular}

The test was found to be statistically significant, $\mathrm{t}(58)=-4.538, \mathrm{p}=0.000$, as the Sig. $p>$ 0.05 , it concludes that the assumption of equal variances holds. Since Sig. $=0.316$ in Table 3.1 , the first line of t-test is considered and denoted as equal variances assumed. These results indicate that night shift employees $(M=145.00, S D=17.146)$ experienced more job stress compared to the day shift employees $(\mathrm{M}=127.73, \mathrm{SD}=11.847)$.

Table 4 Illustrating the descriptive statistics of Job Satisfaction Scale.

\begin{tabular}{|l|l|l|l|l|}
\hline \multirow{3}{*}{ JSS } & Shift-Schedule & N & Mean & Std. Deviation \\
\cline { 2 - 5 } & Dayshift & 30 & 71.10 & 11.040 \\
\cline { 2 - 5 } & Nightshift & 30 & 56.00 & 11.765 \\
\hline
\end{tabular}

Table 4.1 Illustrating the Independent Samples t-test of Occupational Stress Index.

\begin{tabular}{|l|l|l|l|l|l|l|}
\hline \multicolumn{2}{|c|}{} & \multicolumn{2}{|l|}{$\begin{array}{l}\text { Levene's Test for } \\
\text { Equality of Variances }\end{array}$} & \multicolumn{2}{l|}{ t-test for Equality of Means } \\
\cline { 3 - 7 } \multicolumn{2}{|c|}{} & F & Sig. & t & df & Sig. (2-tailed) \\
\hline \multirow{3}{*}{ JSS } & $\begin{array}{l}\text { Equal variances } \\
\text { assumed }\end{array}$ & .032 & .859 & 5.126 & 58 & .000 \\
\cline { 2 - 7 } & $\begin{array}{l}\text { Equal variances } \\
\text { not assumed }\end{array}$ & & & 5.126 & 57.767 & .000 \\
\hline
\end{tabular}


The test was found to be statistically significant, $t(58)=-5.126, p=0.000$, as the Sig. > 0.05 , it concludes that the assumption of equal variances holds. Since Sig. $=0.859$ in Table 4.1 , the first line of t-test is considered and denoted as equal variances assumed. These results indicate that night shift employees $(\mathrm{M}=56.00, \mathrm{SD}=11.765)$ experienced low job satisfaction compared to the day shift employees $(\mathrm{M}=71.00, \mathrm{SD}=11.040)$.

As the Sig. (2-tailed) $\alpha<0.05$, the null hypothesis is rejected "There is no difference between Job Stress, Psychological Distress, and Job Satisfaction among night shift workers compared to day shift workers", and alternative hypothesis is accepted "Employees working night shift will have more Job Stress and Psychological Distress, and Low Job Satisfaction than day shift". These findings are in correspondence with (Kim, et al., 2002) who examined the impact of shift work on physical and psychological health, quality of life quality, stress, and sleep. The results suggested that physical and psychological distress, and sleep problems are suffered mainly by shift-workers compared to non-shift workers that affect the quality of life.

The study by (Ryu, et. al., 2017) determined the relationship between mental health and shift work particularly insomnia, suicidal ideation, and depression among South Korea workers. The results indicated that shift work presents higher mental health problems and sleep disturbance. Another research which supports the findings of the present research is of (Verma, et. al., 2018) who conducted a comparative study of injuries and shift work among nurses. This study suggests that female nurses working during night hours exhibit job dissatisfaction and reduced psychological well-being compared to day shift. At night times, there is seen to have less competitiveness and supervision, which leads to absenteeism, boredom, sleep problems, work-life imbalance, productivity, occupational stress, and psychological distress. This is why stress, psychological distress, and job dissatisfaction is more evident in night shift employees compared to day shift.

\section{Pearson's Product Moment Correlation}

Table 5 Illustrating Pearson's Product Moment Correlation between GHQ-28, OSI, and JSS.

\begin{tabular}{|l|l|l|l|l|}
\hline \multirow{4}{*}{ GHQ-28 } & Pearson Correlation & GHQ & OSI & JSS \\
\cline { 2 - 5 } & Sig. (2-tailed) & 1 & $.541^{* *}$ & $-.589^{* *}$ \\
\cline { 2 - 5 } & $\mathrm{N}$ & 60 & .000 & .000 \\
\hline \multirow{3}{*}{ OSI } & Pearson Correlation & $.541^{* *}$ & 60 & 60 \\
\cline { 2 - 5 } & Sig. (2-tailed) & .000 & & $-.669^{* *}$ \\
\cline { 2 - 5 } & $\mathrm{N}$ & 60 & 60 & .000 \\
\hline \multirow{3}{*}{ JSS } & Pearson Correlation & $-.589^{* *}$ & $-.669^{* *}$ & 60 \\
\cline { 2 - 5 } & Sig. (2-tailed) & .000 & .000 & 60 \\
\cline { 2 - 5 } & $\mathrm{N}$ & 60 & 60 & 6 \\
\hline
\end{tabular}

**. Correlation is significant at the 0.01 level (2-tailed).

The correlation in the main diagonal that is GHQ-28 with GHQ-28, OSI with OSI, and JSS with JSS are all equal to 1 . This is the case because a variable is always perfectly correlated with itself. The findings indicate a positive correlation between GHQ and OSI ( $r=0.541)$, and negative relation between GHQ and JSS $(r=-0.589)$, and OSI and JSS $(r=-0.669)$, which were all significant at the 0.01 level. 
Thus, the alternative hypothesis is accepted "Employees working the night shift will have more Job Stress and Psychological Distress, and low Job Satisfaction than day shift", as when the Psychological Distress and Occupational Stress is high, there will be low Job Satisfaction. The research analysis is in consonant with (Ferri, et. al., 2016) study on the shift work's impact on physical and psychological health of nurses. It indicates that nurses working in rotating night shift report higher job dissatisfaction, sleeplessness, and detrimental health effects. The finding is also in agreement with (Singh \& Rapheileng) who studied job satisfaction and occupational stress, concluding a negative correlation between both variables. (Srivastava 2010) study examining the mental health and stress among night shift employees also concurs with the findings of the present research. As the study concludes, that night shift and shift work are major sources of job stress affecting human circadian system and creating numerous psychosocial, psychological, and physiological problems.

(Schwab 1996), states that job stress presents adverse outcomes such as decline in work quality, illness, job dissatisfaction, staff turnover, and absenteeism. So when the job stress is high, there is psychological distress and lower job satisfaction among employees, that affects the job performance and turnover, which is concluded by the research findings of the study.

\section{CONCLUSION}

The purpose of the present study was to understand and determine the significant relationship between job stress, psychological impact, and job satisfaction among day-shift and night-shift employees. During night shift there is less supervision which affects the job performance, productivity, and satisfaction. Thus, results of the analysis indicate that the employees working in night shift have more Job Stress and Psychological Impact, and Low Job Satisfaction than day shift. Based on the findings, various measures are recommended to increase job satisfaction, reduce job stress and psychological distress in the following manner:

1. Identifying the stressful factors or stressors in order to optimize them.

2. Offering adequate supervision and staff support.

3. Regular monitoring should be held with proper feedback and evaluation to help promote mental well-being, reduce stress levels, and improve job environment.

\section{REFERENCES}

Ákerstedt, T., \& Wright, K. P. (2009). Sleep loss and fatigue in shift work and shift work disorder. Sleep medicine clinics , 4 (2), 257-271.

Blaug, R., Kenyon, A., \& Lekhi, R. S. (n.d.). Stress at work. The work foundation .

Costa, G. (2010). Shift Work and Health: Current Problems and Preventive Actions. Safety and health at work , 1 (2), 112-123.

Costa, G. (1996). The impact of shift and night work on health. Applied ergonomics , 27 (1), 9-16.

Culpepper, L. (2010). The social and economic burden of shift-work disorder. Journal of Family practice , 59 (1), S3-S3.

Drake, C. L., Roehrs, T., Richardson, G., Walsh, J. K., \& Roth, T. (2004). Shift work sleep disorder: prevalence and consequences beyond that of symptomatic day workers. Sleep , 27 (8), 1453-1462.

Edwards, D., \& Burnard, P. (2003). A systematic review of stress and stress management interventions for mental health nurses. Journal of advanced nursing , 42 (2), 169200. 
Ferri, P., Guadi, M., Marcheselli, L., Balduzzi, S., Magnani, D., \& Di Lorenzo, R. (2016). The impact of shift work on the psychological and physical health of nurses in a general hospital: a comparison between rotating night shifts and day shifts. Risk management and healthcare policy , 9, 203.

Folkard, S., Monk, T. H., \& LOBUAN, M. C. (1979). Towards a predictive test of adjustment to shift work. Ergonomics , 22 (1), 79-91.

Hans., S. (1975). Stress and distress. Comprehensive therapy, 1 (8), 9-13.

Judge, T. A., Thoresen, C. J., Bono, J. E., \& Patton, G. K. (2001). The job satisfaction-job performance relationship: A qualitative and quantitative review. Psychological bulletin, 127 (3), 376.

Kang, M. Y., Kwon, H. J., Choi, K. H., Kang, C. W., \& Kim, H. (2017). The relationship between shift work and mental health among electronics workers in South Korea: A cross-sectional study. PloS one, 12 (11).

Kepler, K. (1994). Achieving job satisfaction: A crisp assessment profile. Thomson Crisp Learning.

Kim, Y. G., Yoon, D. Y., Kim, J. I., Chae, C. H., Hong, Y. S., Yang, C. G., et al. (2002). Effects of health on shift-work: general and psychological health, sleep, stress, quality of life. . Korean Journal of Occupational and Environmental Medicine , 14 (3), 247-256.

Kim, Y. G., Yoon, D. Y., Kim, J. I., Chae, C. H., Hong, Y. S., Yang, C. G., et al. (2002). Effects of health on shift-work: general and psychological health, sleep, stress, quality of life. Korean Journal of Occupational and Environmental Medicine , 14 (3), 247-256.

Lee Larson, L. (2004). Internal auditors and job stress. Managerial Auditing Journal , 19 (9), 1119-1130.

Luthans, F. (2011). Organizational behavior: An evidence-based approach (12th ed.). New York: McGraw-Hill/Irwin.

Rameshbabu, A., Reddy, D. M., \& Fleming, R. (2013). Correlates of negative physical health in call center shift workers. Applied Ergonomics , 44 (3), 350-354.

Ryu, J., Jung-Choi, K., Choi, K. H., Kwon, H. J., Kang, C., \& Kim, H. (2017). Associations of shift work and its duration with work-related injury among electronics factory workers in South Korea. International journal of environmental research and public health , 14 (11), 1429.

Saijo, Y., Ueno, T., \& Hashimoto, Y. (2008). Twenty-four-hour shift work, depressive symptoms, and job dissatisfaction among Japanese firefighters. American journal of industrial medicine , 51 (5), 380-391.

Schwab, L. (1996). Individual hardiness and staff satisfaction. Nursing Economics , 14 (3), 171-173.

Schwartz, J. R. (2010). Recognition of shift-work disorder in primary care. Journal of Family Practice, 59 (1), S18-S18.

Scott, A. J., Monk, T. H., \& Brink, L. L. (1997). Shiftwork as a risk factor for depression: a pilot study. International journal of occupational and environmental health , 3 (Supplement 2), S2-S9.

Singh, K. T., \& Rapheileng, A. S. (n.d.). Job satisfaction and occupational stress among public and private bank employees in Manipur.

Srivastava, U. (2010). Shift work related to stress, health and mood states: a study of dairy workers. Journal of Health Management, 12 (2), 173-200.

Sutherland, V. J., \& Cooper, C. L. (1990). Understanding stress: A psychological perspective for health professionals. . Chapman \& Hall/CRC. 
Shift-work job stress, psychological distress, and job satisfaction among employees

Verma, A., Kishore, J., \& Gusain, S. (2018). A comparative study of shift work effects and injuries among nurses working in rotating night and day shifts in a Tertiary Care Hospital of North India. Iranian journal of nursing and midwifery research , 23 (1), 51.

\section{Acknowledgments}

The author appreciates all those who participated in the study and helped to facilitate the research process.

\section{Conflict of Interest}

The author declared no conflict of interest.

How to cite this article: Dodia P. \& Parashar N. (2020). Shift-work job stress, psychological distress, and job satisfaction among employees. International Journal of Indian Psychology, 8(3), 1215-1223. DIP:18.01.127/20200803, DOI:10.25215/0803.127 